\title{
The Role of Health Literacy in Achieving Oral Health for Elders
}

\section{Citation}

Rudd, Rima, and Alice M Horowitz. "The Role of Health Literacy in Achieving Oral Health for Elders." Journal of Dental Education 69, no. 9 (2005): 1018-21.

\section{Permanent link}

http://nrs.harvard.edu/urn-3:HUL.InstRepos:33942515

\section{Terms of Use}

This article was downloaded from Harvard University's DASH repository, and is made available under the terms and conditions applicable to Other Posted Material, as set forth at http:// nrs.harvard.edu/urn-3:HUL.InstRepos:dash.current.terms-of-use\#LAA

\section{Share Your Story}

The Harvard community has made this article openly available.

Please share how this access benefits you. Submit a story.

\section{Accessibility}




\title{
The Role of Health Literacy in Achieving Oral Health for Elders
}

\author{
Rima Rudd, M.S.P.H., Sc.D.; Alice M. Horowitz, Ph.D. \\ Abstract: A mismatch between the literacy skills of individuals and the demands of oral health services may erect an unnecessary \\ barrier to preventive care and treatment. Findings from the 1992 survey of adult literacy in the United States indicate that more \\ than two-thirds of adults over the age of sixty were limited in their ability to use written health materials in prose format, had \\ problems finding and processing quantitative information, and were very limited in their ability to use documents such as forms, \\ lists, charts, and graphs. Thus, many older adults face barriers to oral care, to needed information, to full participation in decision \\ making and informed consent, and for follow-up activities. The pathways between literacy and health outcomes are being \\ examined, and the body of literature linking literacy to health continues to grow. However, similar studies examining literacy and \\ oral health outcomes have not yet been undertaken. Research in this area might well begin with consideration of the skills needed \\ to perform important oral health tasks. Rigorous studies of the impact of improved communication strategies on elders' access to \\ care, participation in services, and action steps would lend insight into needed change. \\ Dr. Rudd is Senior Lecturer on Society, Human Development, and Health at the Harvard School of Public Health; Dr. Horowitz \\ is an Educational Specialist in the Population Research and Health Promotion Branch, Division of Clinical Research and Health \\ Promotion, National Institute of Dental and Craniofacial Research, National Institutes of Health. Direct correspondence and \\ requests for reprints to Dr. Rima Rudd, Department of Society, Human Development, and Health, Harvard School of Public \\ Health, 677 Huntington Ave., Boston, MA 02115; 617-432-1135 phone; 617-432-3123 fax; rrudd@hsph.harvard.edu.
}

$\mathrm{O}$ ver the past fifty years, the U.S. population has grown older, and current predictions indicate that by 2050 one in five Americans will be elderly. As this segment of the population increases, so too will the need for more services, most especially for the treatment and management of chronic and acute health conditions. ${ }^{1}$ As older adults engage with a variety of health-related services, they face complex demands that require all consumers to use sophisticated materials and documents as they seek information, make decisions, understand rights and responsibilities, manage illnesses, and engage in self-care. These activities require sophisticated literacy skills. However, as has been documented in the findings from the National Adult Literacy Survey, many U.S. adults, and older adults in particular, do not have the literacy skills needed to use complex health materials. ${ }^{2}$ The Institute of Medicine describes health literacy as a shared function of social and individual factors. ${ }^{3}$ Three decades of studies indicate that social factors in health contexts are demanding ${ }^{4}$ and that adults' ability to use everyday health-related materials is limited. ${ }^{5}$

The burgeoning field of health literacy is providing evidence of links between literacy and health outcomes. ${ }^{6}$ Increased attention to literacy may offer insight for addressing oral health needs of older adults and for reducing barriers to care. We know that some of the obvious barriers that inhibit the use of known preventive regimens or access to oral health care in- clude lack of money and dental insurance. Moreover, most state Medicaid programs do not provide dental services to adults, and many oral health providers will not accept Medicaid. ${ }^{7}$ However, we need not place additional untoward burdens on the shoulders of elder adults by allowing literacy issues to get in the way.

Health literacy, as a barrier to health-related action and a contributor to poorer outcomes, is of particular interest and concern for vulnerable populations. Amongst them are elders. The following discussion focuses on possible links between literacy and the oral health status of older adults.

\section{Oral Health}

Oral health, a key component of one's health and well-being, enhances self-image, quality of life, and nutrition..$^{7-9}$ However, despite a broad array of preventive measures for most oral diseases, many U.S. adults do not use the proven preventive procedures and do not or cannot use the oral health care system. Furthermore, surveys indicate that the general public is not aware of the relationship between oral health and general health or that most oral disease can be prevented or controlled. ${ }^{7}$

Use of dental care has increased among elders over the past two decades, as has the proportion of elders keeping their teeth. However, in the mid- 
1990s, 30 percent of older men and 27 percent of older women had untreated dental caries. Furthermore, 26 percent of elders had no natural teeth. The prevalence of tooth loss was higher among those with lower socioeconomic status and among minority population groups. ${ }^{7-8}$ The oral health objectives of Healthy People 2000 were not met. ${ }^{10}$ One of the reasons for this lack of success may be poor communication. Literacy-related issues may likewise play a role in our attempts to achieve the goals and objectives of Healthy People 2010.

Little attention has been given to the materials addressing oral health issues and those used in dental health settings. ${ }^{11}$ Literacy-related issues may erect barriers to preventive action, access for care, and effective follow-up activities. Oral health materials include newspaper and magazine articles focused on oral health issues (such as prevention or new treatment options), forms used in the process of obtaining services and entering care, information shared about examination findings and recommended action, consent documents for specific processes, and directions for follow-up action and care.

\section{Literacy Skills of Adults Age Sixty and Older}

The large-scale literacy surveys conducted in twenty-two industrialized nations since the early 1990s focus on adults' ability to use print materials found in everyday life. The materials used in these assessments were drawn from activities such as banking or shopping and used commonly found print materials such as safety postings, product labels, deposit slips, or newspaper articles. Materials ranged from simple (such as a social security card) to complex (such as an editorial). The tasks adults were asked to undertake similarly ranged from easy to complex. For example, locating the name of a country in a newspaper article is less complex a task than using information on a medicine package to determine the maximum daily dosage to give a child. ${ }^{12}$

Scores on the National Adult Literacy Survey (NALS) indicate that the vast majority of U.S. adults read and report engaging in a variety of literacyrelated practices. However, the average score for U.S. adults was 273 out of a possible score of 500, indicating that about half of U.S. adults have some difficulty using print materials to accomplish many everyday tasks. At the same time, the average score for adults age sixty and over was 232 . As shown in Table 1,71 percent of adults age sixty and older demonstrated difficulty with print materials, and most (four out of five older adults) demonstrated difficulty using documents such as forms, lists, charts, and graphs. ${ }^{12}$

Literacy and Health in America, an analysis based on the large-scale surveys noted above but focused only on adults' ability to use materials for health-related tasks, indicates that adults over the age of sixty-five have an average health-related literacy score of 224 out of a possible score of 500, compared with adults between the ages of thirty and fortyfive, who have an average score of $282 .{ }^{5}$ The health literacy skills among older adults do vary based on education, health-related limitations, and access to resources. As shown in Table 2, the scores of adults who are retired and receiving social security differ based on education and access to resources. For example, retired adults with education beyond high school and with added resources from interest or dividends have higher than average scores (285). Older adults without added resources and without a high

Table 1. Average literacy proficiencies for older adults

\begin{tabular}{|c|c|c|c|c|c|c|c|}
\hline \multirow[t]{2}{*}{ Type } & \multirow{2}{*}{$\begin{array}{c}\text { Average } \\
\text { Score for } \\
\text { Older Adults } \\
\quad(\geq 65)\end{array}$} & \multirow[t]{2}{*}{$\begin{array}{l}\text { Average } \\
\text { Score for } \\
\text { All Adults }\end{array}$} & \multicolumn{5}{|c|}{$\begin{array}{l}\text { Percent by NALS Levels/Score Groups } \\
\text { for Older Adults }\end{array}$} \\
\hline & & & $\begin{array}{l}\text { Level } 1 \\
{[0-225]}\end{array}$ & $\begin{array}{l}\text { Level } 2 \\
\text { [226-275] }\end{array}$ & $\begin{array}{c}\text { Level } 3 \\
{[276-325]}\end{array}$ & $\begin{array}{c}\text { Level } 4 \\
{[326-375]}\end{array}$ & $\begin{array}{c}\text { Level } 5 \\
{[376-500]}\end{array}$ \\
\hline Prose Continuous texts, e.g., newspaper article & 238 & 272 & $39 \%$ & $32 \%$ & $21 \%$ & $6 \%$ & $1 \%$ \\
\hline Document Lists, tables, charts, graphs, forms & 224 & 267 & $47 \%$ & $33 \%$ & $16 \%$ & $4 \%$ & $0 \%$ \\
\hline Quantitative Basic math calculations & 236 & 271 & $41 \%$ & $27 \%$ & $22 \%$ & $8 \%$ & $2 \%$ \\
\hline
\end{tabular}

Source: Information drawn from Figure 1-1 in Literary of older adults in America. Washington, DC: U.S. Department of Education, National Center for Education Statistics, National Adult Literacy Survey, 1992. 
Table 2. Health literacy skills of U.S. adults by education and resources*

\begin{tabular}{lccc} 
Population Groups & $<$ HS & HS/GED & $>$ HS \\
\hline Working adults (with resources) & 273 & 291 & 321 \\
Working adults (without resources) & 218 & 267 & 293 \\
Elders (with resources) & 216 & 257 & 285 \\
Non-working poor (without resources) & 217 & 264 & 281 \\
Elders ( $\geq 65$ ) (poor, without resources) & 188 & 240 & 261
\end{tabular}

* Resources are measured as having income from a savings account, dividends, or retirement fund.

Source: Rudd RE, Kirsch I, Yamamoto K. Literacy and health in America: a policy report. Princeton, NJ: Educational Testing Services, 2004.

school degree have very limited literacy skills, with an average score of 188 . Overall, the majority of older adults would have considerable difficulty dealing with a broad range of health-related tasks. ${ }^{5}$

\section{Possible Links Between Literacy and Oral Health}

A mismatch between average skills of individuals and the literacy-related demands of services erects an unnecessary barrier to care and services. Such a mismatch also stands as a violation of basic communication principles. A reader does not have an opportunity to engage in an iterative process with a writer. Unfortunately, the reading level of public health, medical, and dental materials (including educational materials, directives, forms, and documents in common use) has been assessed at reading grade levels that exceed the average reading skills of adults in the United States. ${ }^{4,11,13-14}$ We must attend to the content, structure, and format of written and spoken communications.

At the same time, public health, medical, and dental professionals must consider many of the underlying assumptions about both the knowledge and skills of the public served. For example, the assumption that adults are uniformly taught about the names and functions of various body systems is belied by the curricula in most K-12 systems. Tasks such as filling out an open entry form, maintaining records and files for insurance applications, reading a chart to calculate appropriate dosage of medicine, or using a calendar or clock to establish a schedule may well involve skills that are beyond those taught in the K-12 systems. ${ }^{3}$ Consequently, the U.S. Depart- ment of Health and Human Services report, "Communicating Health," calls for change and improvements in the education systems as well as in the reading levels of health materials, the communication abilities of health professionals, and the characteristics of health delivery systems. ${ }^{15}$

The exact pathways between literacy and oral health outcomes have not yet been established through rigorous studies. Yet, when adults cannot access information related to important scientific findings or recommendations for preventive measures and self-care; when they are stymied by complicated forms related to payment, insurance, and history; and when they are prevented from offering true informed consent by legal and scientific jargon, words may well be getting in the way. Needed action steps involve clear communication practices, consideration of the skills needed to perform important oral health tasks, and rigorous studies of the impact of improved communication strategies on elders' knowledge of available options, understanding of consequences, behaviors, or oral health status.

Increased attention to literacy within the oral health arena has been driven, in part, by legal and ethical concerns for adequate protection of human subjects and patient autonomy in informed consent procedures, for the development of communication strategies, and for supporting equal access to care and services. In addition, community health may be at stake if community members are hampered in their attempt to access and understand public health issues such as community water fluoridation. The importance of oral health literacy is addressed in Healthy People 2010, ${ }^{8}$ Oral Health in America: A Report of the Surgeon General, ${ }^{7}$ A National Call to Action to Promote Oral Health, ${ }^{9}$ and the Institute of Medicine report, Health Literacy: a Prescription to End Confusion. ${ }^{3}$ But it remains with oral health practitioners, academicians, researchers, and policymakers to set a research and action agenda and to explore and evaluate efficacious actions that will improve the oral health of elders. This research agenda will be strengthened by attention to health literacy. 


\section{REFERENCES}

1. Paston PN, Makuc DM, Reuben C, Xia H. Chartbook on trends in the health of Americans. In: Health, United States, 2002. Hyattsville, MD: National Center for Health Statistics, 2002.

2. Literacy of older adults in America: results from the national adult literacy survey. NCES 97-576. Washington, DC: U.S. Department of Education, National Center for Education Statistics, 1996.

3. Committee on Health Literacy, Institute of Medicine. Health literacy: a prescription to end confusion. Washington, DC: National Academies Press, 2004.

4. Rudd RE, Moeykens BA, Colton T. Health and literacy: a review of medical and public health literature. Chapter 5 in: Comings JP, Garner BC, Smith CA, eds. The annual review of adult learning and literacy. San Francisco: Jossey-Bass, 2000.

5. Rudd RE, Kirsch I, Yamamoto K. Literacy and health in America: a policy report. Princeton, NJ: Educational Testing Services, 2004.

6. Berkman ND, DeWalt DA, Pignone MP, Sheridan SL, Lohr KN, Lux L, et al. Literacy and health outcomes. Evidence report/technology assessment, no. 87. AHRQ Publication No. 04-E00t-2. Rockville, MD: Agency for Healthcare Research and Quality, 2004.

7. Oral health in America: a report of the surgeon general. Rockville, MD: U.S. Department of Health and Human Services, National Institute of Dental and Craniofacial Research, National Institutes of Health, 2000.

8. U.S. Department of Health and Human Services. Healthy people 2010. $2^{\text {nd }}$ ed. 2 vols. Washington, DC: U.S. Government Printing Office, November 2000.

9. A national call to action to promote oral health. NIH Publication no.03-5303. Rockville, MD: U.S. Department of Health and Human Services, Public Health Service, Centers for Disease Control and Prevention and the National Institutes of Health, National Institute of Dental and Craniofacial Research, May 2003.

10. National Center for Health Statistics. Healthy people 2000 final review. Hyattsville, MD: Public Health Service, 2001.

11. Emmer C. Oral health literacy annotated bibliography. Harvard School of Public Health: Health Literacy Website, 2003. At: www.hsph.harvard.edu/ healthliteracy/literature/ lit_oral.html. Accessed: January 2005.

12. Kirsch IS, Jungeblut A, Jenkins 1, Kolstad A. Adult literacy in America: a first look at the results of the National Adult Literacy Survey. Educational Testing Services, National Center for Health Statistics. Washington, DC: Office of Educational Research and Improvement, 1993.

13. Chung V, Horowitz AM, Canto MT, Siriphant P. Oral cancer educational materials for the general public. J Public Health Dent 2000;60:49-52.

14. Mongeau SW, Horowitz AM. Assessment of reading level and content adequacy of oral cancer educational materials from USAF dental clinics. J Cancer Educ 2004;19:29-36.

15. Communicating health: priorities and strategies for progress. Washington, DC: U.S. Department of Health and Human Services, July 2003. 